\title{
Health in Prospect High-tech Medicine, Life Enhancement and the Economy of Hope
}

\author{
Ilpo Helén
}

In this article, high-tech medicine is approached as life enhancement technology. Today, the most advanced medical technology operates on the level of cells and molecules, thus opening unprecedented prospects not only for curing and preventing illness but also for shaping of life itself.Thus, high-tech medicine seems to offer more efficient means to remove the restrictions of physical abilities and to improve and 'repair' vital processes. It promises to enhance life. The essay focuses on two aspects of this development. The first issue analysed is the tendency in high-tech medicine to connect medical progress to augmentation of personal choices on health and life improvement. Further, also the economical side is discussed by focusing on the role the patients' activism in high-tech medical business. The argument of the essay is the following: the power to raise hopes for new cures and better life in people is a crucial characteristic of today's high-tech medicine. Consequently, it is the people living in such a hope who provides uel for both technological progress and profitseeking in today's medicine.

Keywords: medical technology, personal health, hope

Medicine offers modern man obstinate, yet reassuring face of his finitude; in it, death is endlessly repeated, but it is also exorcised; and although it ceaselessly reminds man of the limit that he bears within him, it also speaks to him of that technical world that is the armed positive, full form of his finitude.

Michel Foucault

With these words, Michel Foucault (1989: 198) summed up an essential fea- ture of modern medicine: it makes us face the fragility of our life and the deficiency of our physical powers, both as a species and individuals. Medical technology not only forewarns of pain and death, but above all, promises both humanity and individual human beings, if not the ability to overcome, then at least protection from and means to rule over illness, physical suffering and death. Thus, the promise to tame human mortality and to control the powers of 'life 
itself' lies at the heart of modern medicine. It is perhaps the most fundamental of all the promises concerning earthly life that the systems of knowledge and belief deriving from the Enlightenment have made to modern man.

Historically, the early advances in modern medicine like the microscope, the $\mathrm{x}$-rays, applications of bacteriology and improved surgical techniques were applied to fight death and morbid diseases - tuberculosis, smallpox and cancer, for example. The practical mission of medicine was to expel lethal and severely impairing diseases from individual and social organisms and to build a wall of medical knowledge and care to protect the vital processes of individuals, populations and society. Modern medicine was epitomised by the late $19^{\text {th }}$ and early $20^{\text {th }}$ century measures to root out contagious diseases, tuberculosis in particular: mass screenings, vaccination programmes, campaigns for improvement of general hygiene and sanatoria. Public health was the focus of such medicine, and bacteriology was its scientific spearhead, in which also the breakthrough of pharmacology was embedded. By the bedside, the progress was most notable in surgery and cancer treatment. All in all, it was death that initially provided raison d'etre for the modern medical technology both in practical and epistemological sense (on the latter, see Foucault, 1989: 141-144, 170172; Canguilhem, 1989: 55-56, 72-75). Hence, our medicine is essentially a science of death (Helén, 2002: 105-107).

The above rationale characterises well even today's medicine. However, a new aspect of medical knowledge and care has emerged, and it is prominent especially in the areas that are in the van- guard of medical research and the development of diagnostic and treatment techniques. Today, the focus of advancing medical technology is less on human mortality and protection of vital processes than on life enhancement.

In this essay, I take a closer look on two aspects of this development. First, I analyse the technological aspect of today's medicine, in particular, the tendency to connect medical progress to augmentation of personal choices on health and life improvement. Then, I move on to the economical side of high-tech medicine. I focus on the issue that is becoming more and more central in health care economy, namely, the role the patients' activism in high-tech medical business. My argument is that the power to raise hopes for new cures and better life in people is a crucial characteristic of hightech medicine. Consequently, it is the people living in such a hope who provide fuel for both technological progress and profit-seeking in medicine today.

\section{Exceeding the Limits of Life}

To illustrate what this new medical life enhancement could be I take up Arthur Frank's (2003) example of a New York podiatrist who offers to her customers surgical operations for modification of the foot to fit in 'gorgeous sandals' or other design shoes. Of course, this kind of treatment represents extravagant cosmetic medicine and can be dismissed as a singular extremity. The example, however, is not trivial regarding a general fact that modern medicine aims to fulfill what we desire and to provide us means and resources to pursue health and longer, fuller, more beautiful and more enjoyable life. Thus, the crucial question 
concerning many forms of modern medical technology is, what does it make possible, or at least realistically imaginable. Frank's example of foot surgery illustrates the change that current advances of medicine are imposing: the scope of 'medically possible' is surpassing the perspective of restoring human vital functions toward efforts to overcome 'natural' or inborn limitations of the individuals and to design oneself even on the biological level. This development is by no means restricted to the marketplace of so-called lifestyle medicine but characterises also molecular medicine, the heart of today's medical science. For example, scientists' visions of extending the normal human life span to even 120-130 years with the help of therapeutic cloning and stem cell technologies (Franklin, 2003) are a clear indication of this trend.

Medical genetics is the display window of the newest medicine. The utilisations of molecular biology in mapping of gene defects causing specific rare diseases or predisposing individuals to common diseases or even 'abnormalities' like alcoholism, obesity or homosexuality, in carrying out genetic screenings and diagnostic DNA tests, and in development of smart drugs and gene therapies are seen to indicate the future course of all medicine. From my perspective, medical genetics is pivotal due to the fact that it requires, even in its routine operations, sophisticated technology of molecular biology (in particular, PCR technique to 'copy' DNA sequences) and information technology. For this reason, it is a prime example of high-tech medicine that ever more profoundly determines what ars medica, i.e. the art of healing, is today. Medical high-tech is not, however, re- ducible to molecular genetics but takes numerous forms. This is exemplified by neurological and psychiatric applications of neuroscience - psychopharmacology, in particular - in which knowledge and techniques of molecular biology are utilised in a framework wider than genetics. The same can be said about in vitro fertilisation, organ transplantation and stem cell technologies, as well as of applications of molecular biology in, for example, research on nutrition physiology. In addition, sophisticated observation and measurement devices from ultrasound scan to computer imaging techniques, new prosthetic materials and new surgical instruments like optic fibres and robots are crucial elements in the advance of medicine today.

State-of-the-art medical technology is accompanied by the visions of the coming revolution in medical science and care that opens up unprecedented possibilities to cure both rare and difficult hereditary conditions and also more common diseases. Such a partisan optimism of defeating illness, most often declared by the advocates of medical genetics, has appeared time and again in the history of modern medicine. Beneath the traditional surface of medical futurology, however, lies the actual promise of molecular medicine, and of high-tech medicine in general, - and that is a novelty. Namely, the spearhead of current medicine is oriented towards fundamental modification of vital processes, and such a pursuit makes it possible to think that 'life itself' is modifiable down to the ultimate levels of cells and molecules.

This aspiration to govern life by moulding vital processes and functions 
is pursued in current medicine in two ways. First, the avant garde molecular medicine tends to be predictive in practice. In other words, it emphasises anticipation and prevention of illness. Assessment of individual 'health risks' by diagnostic tests holds the key position: advanced techniques like ultrasound scanning, computer imagining and DNA or other biochemical tests enable the detection of possible cause of a disease from the individual's 'life stock' and evaluation of probability for its onset before there are any notable or experienced symptoms of ill-health in the patient. Then, this 'presymptomatic illness' (Nelkin, 1993: 189) can be treated by prophylactic measures. Foetal diagnostic testing and antenatal screening, and socalled selective abortion related to them, form a conspicuous example of this kind of procedure. Also the treatment of PKU disease follows the same rationale. The disease is a hereditary disorder of amino acid metabolism causing a severe disturbance in the development of the brain and central nervous system. In order to treat the condition, the newborn belonging to a 'risk family' is tested and the onset of the disease is prevented by a special diet. The progress of molecular genetics and neuroscience has raised hopes of the same kind of presymptomatic detection and treatment of, for example, asthma, diabetes, schizophrenia or even depression.

The second aspect of life moulding in current medicine is related to knowledge and techniques that enable persons to overcome, replace or circumvent their existing 'deficiency', either inborn or caused by an accident or illness, or even characteristics that fit within limits of normal variation. Growth hormone medication for children with 'short stature' whose height is just within or below the normal variation of growth, approved for marketing by the U.S. authorities in 2003 (FDA, 2003), is an example of such medicine. Techniques like this are means to improve or strengthen vital processes and physical capabilities, or even add new ones. In other words, we are talking about removing the limitations of the human body and vitality on a personal level. This feature is not restricted to state-of-the-art medical technology: spectacles are a commonplace example of such a technique, as well as the contraception pill and insulin treatment for diabetes which are applications of endocrinology, the medical high-tech of the 1920s and 1930s. Further, plastic surgery, sports medicine, infertility treatment and psychopharmacology provide numerous examples of advanced medical technology that serves body modification, enhancement of physical performance, elimination of 'natural' insufficiency or making up one's personality - in a word, aspirations to change what a living person is and what he or she is capable to do.

The fact that the borderline between lifestyle medicine and 'proper' medicine is nowadays blurred is manifested most clearly in the latter fields of medicine. For example, the same techniques of plastic surgery are deployed both in face lifting and repairing of damages of severe burn injuries. Besides such apparent similarities, however, there is a more fundamental connection between the two medical orientations, stemming from the basic characteristics of today's most advanced medical technology. Namely, our high-tech medicine - or, rather, the promise it makes - is trans- 
gressive and utterly focused on the individual. The forefront medicine aims to shift or even remove the limits of life, that is, to transgress the limitations of human capacity to deploy vital forces and modify vital processes. To considerable extent, these efforts are directed to the personal level. In medical science and 'respectable' institutions of medical care, assessment of the person's health risk and mapping of his or her potential illhealth are pivotal operations. The vision for future is personally designed biomedical care, perhaps including a personal health diet, on the basis of personal genome mapping. In the marketplace of lifestyle medicine, the focus is on personal modifiability, instead of risk. Ever more sophisticated and 'scientifically proved' means to shape different parts of the body, natural metabolism or moods are constantly introduced, and services of personal assessment, guidance and training for the use of marketed devices or programmes are also provided. Both modes of medical hightech seek to show each individual his or her personal vital quality and the risks and potential inadequacies included in it. In addition, 'proper' and lifestyle medicine are parallel also in their attempts to augment new possibilities to improve and increase the quality of personal life, also in biological sense, for the individuals to choose.

Still today, 'medicine offers modern man (...) face of his finitude' (Foucault, 1989: 168); regarding current high-tech medicine, however, the finitude of man refers not primarily to mortality but to the limits of knowledge of life and the bounds of controllability and modifiabilty of vital processes. Furthermore, medical hightech is articulated, especially in the clini- cal use, as a combination of prognosis and promise concerning the individual's life and health. Genetic and foetal diagnostic tests, infertility treatment and sex reassignment procedures exemplify well the prognostic nature of today's medicine: predictive diagnosis (based on chromosome analysis, for example) revealing the person's probability to fall ill with certain disease and assessment of repairability of the person's 'deficiency' are the core operations of the current biomedicine.

Thus, medicine has today the power to tell the person's vital destiny, derived even from the level of the genes. Yet, advanced medical technology also provides its clients with opportunities to overcome or change that destiny, or means of coping with it. The task of a person is to choose between options or, rather, promises - to enhance one's own life.

\section{Technology and Personal Choices}

The term 'medical technology' underlines technicality of the art of healing. Besides the capability of moulding objects, 'technics' refers to means and capability to unveil being - or life, in the context of our discussion - in a form different from that in which it naturally expresses itself. This is the quality that all specific techniques share. In modern high-tech medicine, however, as in other modes of modern technology, this exposure (for example, the isolation of tuberculosis bacteria or discovery of the functions of neurotransmitters in the brain) is inseparable from the challenge that technics presents to being and life. The purpose of challenging is to exploit being and life as forces and powers, an 'en- 
ergy', in intensification and modification - in production - of their existing forms. This requires that being and life are not conceived of and worked upon as objects to be encountered but as a 'standing reservoir'. (Heidegger, 1962; Taminiaux, 1982: 134-141; Dean, 1996: 57-60; Helén, 2004: 46-47)

This feature of technicality will be increasingly highlighted as the forefront of medicine becomes more and more detached from the medical science embedded epistemologically and practically in death (see above). Undoubtedly, the most convincing results of current medical genetics are related to detection of gene defects causing severe and, mostly, mortal hereditary diseases. Certainly, research on cell death (or 'apoptosis') is in the vanguard of biology and medical science today (Landecker, 2003). It is essential, however, that knowledge of medical genetics and other high-tech medicine is based on manipulation of the basic elements and processes of life. Here medical science follows molecular biology, in which knowledge on vital processes is inseparable from procedures and devices that change vital functions of an organism or even produces new kinds of functions or organisms and this has been so for over half a century. Transgenic or knock out mice, DNA sequences outside organism produced by the PCR technique, or immortal stem cell lines exemplify well the basis of knowledge in current biology and biomedicine. The assumption is that knowledge of processes of life can be achieved only so far as those processes are subjected to technical manipulation. In addition, molecular level knowledge is inaccessible without sophisticated equipment for manipulation, measurement and observation. Thus, knowledge of health and ill-health in today's medicine is inseparable from techniques that mould, create life. (Rheinberger, 1995; Haraway, 1997; Rabinow, 1998: 140-142; Franklin and Lock, 2003: 13-14)

The combination of the scientific pursuit for the truth on life and experimentation with the potentials to 'improve' life offered by 'life itself' has a power to transform life and the living to resources for transgressive modulations of the social, psychological and biological bounds of human existence. Further, it implies that vital processes and human beings are conceived of as a standing reservoir. Since the current high-tech medicine focuses on individual and emphasises personalised health care, it deploys this power to generate resources for the individuals to change themselves. So, if human vitality is today a standing reservoir gathered together by medical technology, it is a reservoir for self-improvement or even self-perfection.

Again, the power of medical technology rests on a promise to push the limits of life 'further' and, by doing so, to provide each and all not eternal but better, even perfect life. This is a subjectifying promise. Its fulfilment requires from individual persons not only the acceptance of medical authority and procedures but also personal change, that is, becoming a medical subject. In this kind of condition, existence is defined in medical terms and human conduct turns into health care. In the context of the earlier mode of modern medicine focusing on fighting mortal diseases, this subjectivisation became actual, for example, through participation in x-ray mass screenings of tuberculosis or in mass health inspections or, for some in- 
dividuals, through subjection to isolation and treatment in tuberculosis sanatorium or to eugenic sterilisation. These measures were accompanied by popular education and propaganda for personal hygiene that underlined self-discipline and toughening of one's body. Being a medical subject meant solely personal conduct to maintain and protect personal vital functions.

Following Hannah Arendt (1958), it could be claimed that modern medical technology restricts vita activa, i.e. human action, so that it is focused only on natural necessities, thus depriving the human being both as a species and individuals freedom and uniqueness. Against this argument, it can be claimed that modern medicine has aimed at and also succeeded in liberating man as a species, communities and individuals from biological necessities. The breakthrough of molecular and other hightech medicine has made the latter aspect even more paramount and related it predominantly to issues of personal health, which today is increasingly defined in terms of self-fulfilment. The current medical technology has painted a vivid landscape of unprecedented freedom of personal choice regarding the necessities of 'life itself' and provided us ever more opportunities - or options - to shape our own lives and control our health. According to Nikolas Rose (2001: 18-19), the 'molecular turn' of biomedicine is accompanied by a new kind of relation to the self and new practices to work upon the self, embedded in projects of body modification requiring sophisticated biomedical technology. At the core of this somatic individuality, there is a notion of personal autonomy as a personal right to use and make ex- periments on the elements of one's own body and 'biology' in order become a different, better, even perfect person. (Novas and Rose, 2000; see Helén, 2004: 44-45.)

Extreme operations of plastic surgery, such as limb lengthening, are obvious examples of practices relating to somatic individuality. In addition, procedures like foetal diagnosis and selective abortion, hormone treatment and surgical operations for sex-reassignment exemplify them well. They point out that claiming new 'health options', in other words, overcoming potential ill-health of one's own body or personal 'normal handicap' (Rabinow, 1996: 98-102) is not simply a choice but a chain of events, consisting of prognoses and probability assessments, technical operations and numerous situations that require personal decision or choice; it can also be painful and agonising, and may raise considerable anxiety in a person (Helén, 2004: 39-42). Further, the medical techniques to shape one's own life not only consist of medication, devices and surgical operations. In many cases, medication, surgical operation or the use of supportive device requires a major change in personal habits, for example, a special diet, physical exercise, a rigid daily routine or self-inspection rehearsals, or a 're-programming' of a whole personal lifestyle. Sarah Franklin's (1997) study on in vitro fertilisation technology and experiences of women undergoing the procedure of infertility treatment depicts vividly this aspect of high-tech medical life enhancement. It also points impressively out that the changes may affect the personal conduct of living so profoundly that they function as techniques of the self (Foucault, 1985: 25-32). 
In other words, the procedures and changes they impose lead the person to problematise and modify what he or she $i s$. Thus, high-tech medicine has power to define and shape the uniqueness of an individual, i.e. personal existence.

The power of biomedicine is derived from its inclination to assent and intensify our ideas of what we desire. It is practical and technical power that augments and produces; and by doing so, it makes possible for us to want more from life as individual persons and even regarding the biological and physical quintessences. These desires not only concern cosmetic aspects of personal existence, and this business is not all about Viagra, liposuction or facelifts. The expectations raised by current medical technology are also related to situations of severe pains, wasting disease or agony, and in these cases high-tech medicine promises relief from a desperate condition. An interview with a woman in BBC's Newsnight in December 2001 illustrates well what kinds of possibilities new medical technology provides in imagining a future and planning one's personal life in agonising situations. The program featured a mother of an autistic son, who said she was going to have a test tube fertilisation for the next child, where the pre-embryos were screened before implantation in the womb, and choose a female because 'the risk of falling ill with autism is far greater with boys than with girls.'

High-tech medicine opens up a view of indefinite transgression of human finitude and shifting the boundaries of life. In this picture, medical technology is presented as irreplaceable. Moreover, it imposes a conduct of living in which each individual is required to take care of the somatic self in an anticipatory manner, as if persons should live their lives beforehand. A common assumption among the medical profession and health authorities is that what people primarily need, in order to take an anticipatory attitude toward their personal health and medical care and to make health choices for future, is information about 'presymptomatic' diseases, potential ill-health and health risks and about options for prevention and cure. The development of diagnostic techniques has considerably increased the scope and accuracy of predictive information that medical institutions can provide to their clients. Many scholars have claimed that sharing such an information leads to biological or genetic responsibilisation of the individual persons that, in turn, provokes feelings of guilt and anxiety (e.g. Beck-Gernsheim, 1996: 289-290; Petersen, 1998; Chadwick, 1999; Lemke, 2000: 251-256; Novas and Rose, 2000: 502-507).

The questions of personal choice and sharing of adequate information to the clients are usually discussed in relation to ethical considerations on the implementation of new medical technology. It is widely accepted that the formal 'bioethical' basis of today's high-tech medicine is the liberal idea of the moral autonomy of the individual. This is manifested by the principles of informed consent and personal choice, which are repeatedly underlined in official guidelines in, for example, antenatal diagnostic testing, genetic counselling, infertility treatment or collecting of blood or tissue samples for genetic or stem cell research. (Faden, 1991; Petersen, 1999: 255-258; Novas, 2003: 89-107.) If, however, we focus on the practice and content of decisions concerning new medi- 
cal technology, what appears to be constitutive for the 'bioethical' dimension of medical high-tech are the particular life situations in which individual persons make choices whether or not to engage oneself to medical investigations or treatments. Hence, effective principles of moral conduct and responsibility that would bear on every person's choice and desire to deploy medical means to enhance one's own life are hardly conceivable. Ergo, ethics is not generalisable but dispersed. Therefore, it seems impossible to establish a definite and general 'code of ethics' for the implementation of new techniques in the contemporary liberal moral order that cherishes the personal freedom of choice. (Helén, 2004: 36-39)

Besides responsibilities, expectations concerning new medical knowledge on and cure for the person's disease-to-be or somatic 'insufficiency' are also involved in this practice of life, with a perspective of hope and despair. The ways women are 'living the IVF treatment' (Franklin, 1997: 101-197) is a telling but not the only example of a novel existential condition, characterised by a mixture of guilt, expectation, agony and hope, that is entirely embedded in the development of biomedical technology and generates new kind of uncertainty that is not about life but about the moulding of life.

\section{Business and Patients}

Today, high-tech medicine is a global industry. The rise of molecular medicine has given an upswing for the commercial side of medicine, especially by intermingling medical science and business more deeply than ever before. There are two major outcomes of this development. First, the role of the big transnational medical enterprises in medical research, especially the pharmaceutical companies, has grown more prominent, and they have significant influence not only as providers of funding, but also as an institutional context where research in high-tech medicine is carried out. Correspondingly, the relative importance of academic medical research and national and other non-profit based sources of funding has been decreased, especially during the past decade. Second, considerable commercial expectations have been targeted on future medical treatments that should result from the progress of molecular medicine and, consequently, high-tech biomedicine has become a major field of investment for venture capital. The infamous case of deCODE Genetics Inc., the company that endeavoured to create the Health Sector Database by combing DNA samples and medical records of the whole Icelandic population for commercial exploitation, shows outstandingly that the forefront of medical science and technology is nowadays invested with hopes not only for health but for profit, as well (Pálsson and Rabinow, 1999; Pálsson, 2002; Rose, 2003; on the hype of biotech business in general, see Brown, 2003).

All the above points are familiar from numerous studies in sociology and anthropology of the current medicine. For example, discussion on the consequences of commodification of genes and other elementary entities and processes of life began already two decades ago (e.g. Yoxen, 1983; Andrews and Nelkin, 2001). Likewise, the concepts of biovalue and biocapital are entering the 
focus of social scientific discussion on medical technology and science. They refer to the tendency of donated organs, blood or tissue samples in medical collections, spare embryos at the infertility clinics or other 'bio-material' to be transformed into objects of exchange, which are seen as a source of potential financial value for the investors and potential use value for those longing for cure for their illnesses. (Waldby, 2000; Franklin, 2001; Franklin and Lock, 2003: 6-11)

I will not, however, discuss these aspects of economy related to medical high-tech. Instead, I focus on the ways the current health care economy encircles the condition of somatic individuality and the related mode of personal conduct. Today's business of advanced medical technology can be conceived of as life enhancement economy that is a fabric of relationships between big transnational enterprises and small entrepreneurs in medical business, institutions of medical care and research, national and international health authorities, medical professions, and patients and their representatives. The relationships between medical research, business and lay people have often been approached as questions of public opinion. The focus of problematisation in both social surveys and public discussion has usually been the ethical approval or disapproval of the new medical technology by the public. In recent years, both the public authorities in different countries and medical enterprises have become concerned about general public suspicion on state-of-the-art medical technology. Also they have preferred to define the issues in terms of ethics, instead of considering them as social or political questions. Thus, both public authorities and business have attempted to make medical high-tech ethically more acceptable by informing and educating people and by developing technical solutions to reduce the application of controversial techniques (e.g. deployment of embryonic stem cells). (Lemke 2000; Franklin 2003)

A noteworthy feature of this economy is the difficulty to maintain a clear demarcation between inventions in life style medicine and 'respectable' medical exploration to find cures for incurable diseases. The crucial question is how people are related and participate in life enhancement business. As said, medical high-tech moulds personal conduct by connecting it to assessment of personal health risks, biological responsibility, choices between new medical options and to anxiety and hope management; by doing so, it imposes a medical subjectivity. So, to what extent and in which forms is this subjectivity also the one engendered by deepening commercialisation of medicine $?^{1}$

When studying how people become engaged in life enhancement economy through their pursuits of personal health and a better life, one aspect of current medical economy is particularly relevant, namely, the activism of the patients' groups (Rabeharisoa and Callon, 2002; Novas, 2003: 202-229). This activism refers to older organisations for patients suffering from severe illness like cancer or bipolar disorder and for their relatives. It also designates new networks and coalitions of people with rare or newly discovered diseases, including persons who carry genetic or other biological 'markers' of risk for particular diseases. In recent decades, these groups have become more active than ever be- 
fore, greatly thanks to two technological advances. The development of genetic medicine and psychopharmacology has boosted the patients' activism in many ways. They have discovered new disorders, provided a large amount of new information about causes and aetiology of various disorders, and developed techniques to test if a person has a 'presymptomatic' illness or if he or she carries a gene default causing a disease. Most importantly, medical science and technology have created new hope for discovering cures or means of relief to many untreatable ailments. In addition, the Internet is a major factor behind the growth of the patients' activism. TheWeb has provided incredible opportunities for establishing networks, communication and information sharing among the people with the same condition or illness, impairment or being in the process of recovery. In a manner familiar from other contexts of Internet use, a certain group of people or phenomenon - in this case, a particular disease or malady - acquires a firmer and even a new mode of existence through websites and online discussion groups. It could be even said that some rare diseases have gained an actual existence outside the passing references in medical textbooks by the virtue of the Internet.

By extending Paul Rabinow's (1996) idea, one can see the increase in the patients' activism and its new forms as emergence of biosociality. By this term Rabinow refers to a new form of constitution of social groups or 'communities' (Rose, 1999: 172-173, 177-179) consisting of persons who are inflicted by the same disease, either by suffering or recovering from it, having a genetic risk to fall ill with it or being kin to a person with the disease in question. In addition, biosociality refers to a new mode of personal identification to such groups or communities and the active involvement of the groups and their individual members in developing new forms of cure for and coping with their either present or future condition.

Of course, this development reflects the general change of position of those seeking medical help from patients to clients and customers who actively seek treatment and make choices and decisions over the procedures available. Regarding high-tech medicine, an interesting aspect of this change is the fact that the patients' advocacy and self-help organisations have entered the field of medical research, actively influencing research policy and design of single research projects. In many cases, medical scientists studying a particular disorder do not consider the group or network of the people with that disease as a representative of outside lay opinion but as a genuine partner or ally in carrying out the research. (Rabeharisoa and Callon, 2002; Novas, 2003: 210-219.)

\section{Self-help for Progress}

From the perspective of research and business in medical technology, there are certain activities of the patients' advocacy and self-help organisations in which an affirmative relationship can be embedded. First, the patients' groups can be very effective in lobbying health authorities and institutions for research funding. The pressure 'from below' can be decisive for getting a marketing permission to a new medication or having it included among the drugs that are compensated to the patient by health 
insurance. In a similar way patient activism can be crucial in requiring funding for research on rare or controversial illnesses. For this reason, medical corporations and researches are eager to form alliance with particular patients' groups and provide them with resources for lobbying. The way Kári Steffánsson, the primus motor of the deCODE Genetics and founder of the Icelandic Health Sector Database, mobilised the Icelandic Multiple Sclerosis Society in his biotech business venture is a well known example of ambivalent partnership of the patients' groups and commercial pursuits (Rose, 2003: 77-80). Furthermore, the process by which post-traumatic stress disorder was accepted in the American Psychiatric Association's Diagnostic and Statistical Manual III (DSM-III), to great extent due to pressure from the coalition of the Vietnam Veterans suffering from the psychical aftermath of combat and psychotherapist who treated them, is a famous, - or, for some, infamous - example of how influential patients' advocacy action can be (Young, 1995: 107116).

Second, the patients' groups can provide indispensable infrastructure for research. They can gather data in a manner that would be very difficult or even impossible to a research group. A biobank consisting of blood and tissue samples, personal medical histories and family diseases histories from voluntary donators that PXE international, an advocacy network for a rare genetic skin disease, have collected (Novas, 2003: 216-219) is an example of the potentials of these organisations. Moreover, the patients' networks can recruit volunteers for experiments and clinical trials of new treatments. This is especially crucial for pharmaceutical research. The engagement of infected gay activists in the experiments on candidates for the HIV medication and their impact on the agenda of virological research and drug development in the 1980s and 1990s is well known (Epstein, 1996; Löwy, 2001: 62-74).

The relationships between medical enterprises and patients' groups through lobbying, collecting research data and recruiting volunteers for experiments or clinical trials are varying and complex. On the one hand, some groups are generously sponsored by medical corporations, where advocacy networks for certain psychiatric disorders are even initiated by them, which is obviously related to market interest of pharmaceutical companies. On the other hand, patients' group actions may challenge the business interests and make the fundamental controversy of health care capitalism between private gain and public good manifest.

Carlos Novas (2003) presents two fine examples of conflicting interests. The first is a lawsuit against the Miami Children's Hospital and its doctor Reuben Matalon, undertaken by several patients' groups and their activists in 2000. The case concerned a patent awarded to $\mathrm{MCH}$ for a new genetic test for Canavan disease. It is a hereditary disease, relatively common among Ashkenazi Jews. In it, deterioration of myelin, or the 'white matter', in the brain causes gradual disintegration of motor skills and mental functioning of the child and eventually makes him or her blind. The story behind the lawsuit is the following: Daniel and Debbie Greenberg, parents of two children with Canavan disease, had organised the collection of blood, urine 
and tissue samples from persons with Canavan disease and their relatives and given them to $\mathrm{MCH}$ and Dr. Matalon for research purposes. The Greenbergs' effort was indispensable for the development of the new genetic test, and when the hospital put a price tag to the test and presented restrictions for its use, the Greenberg's and the organisations that helped them sued the hospital and the doctor arguing that the profit seeking by the latter violated the interest of the Jewish community and the public good. (Novas, 2003: 219-223)

The second example has a more positive tone. It is related to the mentioned biobank of PXE disease, collected by the PXE international. The patients' network has established strict terms and a procedure of approval for researchers who wish the access to the database. The researchers have to accept the joint possession of intellectual property that may outcome from the research and a joint patent application ensuring that licensing fees are kept to minimum or even free so that the new tests or treatment resulting from the research would be accessible for all in need of them. In addition, the possible profit should be distributed among the collaborators of the research. This is an example of the alliance of researchers and a patients' group that would have power to resist commercial interests and the logic of profit seeking and, instead, to make advanced medical technology affordable and accessible to all in need. (Novas, 2003: 216219)

There is the third aspect in the patients' networks and groups, which makes them attractive for medical business and the related research. When the patients' organisations try to reach out not only to persons suffering from specific diseases, disorders or impairments but also potential patients, they bring together prospective consumer segments. 'Potential' here refers both to persons who might use medication, a device or treatment provided by a company as remedy for his or her ailment and to persons who might be at risk to fall ill with a disease to which a company is either marketing a new cure or carrying out research to find one. The latter mode is interesting for two reasons. First, it is congruent with the predictive orientation of high-tech medicine (cf. above). In addition, it is related to the opening of an 'interface' through which individual persons get involved with social group formation, identification and networking to which Rabinow referred by the term 'biosociality'. Both the patients' advocacy and self-help groups and big medical corporations provide this interface, and in a strikingly similar form. Both in a patients' group website or leaflet and in a corporate website, leaflet or TV commercials, persons can come across the same type of list of symptoms or other features meant to help them make self-inspection of whether or not they possibly belong to a risk family and are potential carriers of a presymptomatic condition (like Huntington's disease) or a gene defect, or whether or not they are at risk to fall ill with a particular disease.

Perhaps such lists of symptoms and similar information educate the public and raise people's 'awareness', but for sure, this happens by invoking doubts and uncertainty about personal health. When facing those lists of symptoms, the person is forced to ask him- or herself 'Is it possible and is it probable that I am 
suffering or will fall ill to this particular disease or disorder?'; and 'What should I do to prevent this from happening?'; and further, 'Do I possibly belong to this group of (potentially) sick people, do I share the same destiny with them, a destiny that presumably is biological, originating from the molecular level of the vital processes of my body?' Regarding life enhancement economy the crucial point is that personal potential for illness, or, in fact, the feeling of uncertainty over personal health, can be transformed into potential for medical research by recruiting people to donate blood or tissue samples or to volunteer in clinical trials. More importantly, it can be turned into commercial potential by introducing people the options to find out their health risks, prevent their future ill-health and improve their lives.

These points are highly relevant as clinical applications and research in molecular medicine are shifting from the rare hereditary diseases to common diseases and life style related disorders. In the field of mental health care, we have witnessed the process by which new categories of mental disorders are 'invented' and, in a due course, either a new selective serotonin-reuptake inhibitor (SSRI) or the new use of an old one is introduced for that particular condition. Do-it-yourself questionnaires and scales for detection of possible symptoms of depressive, anxiety or attention disorders, syndromes from Asperger to Tourette, and even manic-depressive illness are overwhelmingly available in popular magazines, the Internet and self-help advice books. In this form, the individuals face the dense flora of mental disorders, and they are compelled to ask if they themselves or their children, part- ners or other loved ones might be suffering from this or that disorder that could originate from 'the brain'.

\section{Conclusion: Valuable Hopes}

In the market place of medical life enhancement, the objects of supply and demand, as well as the objects of profit seeking, are not primarily certain drugs or medical devices but prospects of health. The production, exchange and, to some extent, also consumption is entirely oriented toward the future. Therefore, this economy is virtual and, in fact, imaginative, based essentially on expectations. None of these characteristics, however, makes the business of hightech medicine different from the hype economy related to bio- and information technology in general (see Brown, 2003). Rather, what makes medical hightech business distinctive is being essentially a 'hope economy' (see Franklin, 2003). This characteristic is closely related to what I presented in the first part of my paper about current medical hightech creating a peculiar reciprocity between existential uncertainty engendered by the new medical technology in the individuals and the hopes for improved quality of life or relief from burdensome life that technological prospects raise. Now, my argument is that it is precisely through uncertainty and hope, embedded in the promise of the progress of health care technology, that people become engaged in commercial drives of medical high-tech. The forms of patient activism described above are the most manifest examples of such involvement.

Therefore, I argue that the cohesive force of medical life enhancement 
economy should be looked for from hope directed to new cures that medical technology promises, from despair and disappointments that are inevitable companions of hope, and from commitment of the individuals to mould their personal conduct according to medical prospects, instead of hype-ridden economic pursuits and interests. The activists of the advocacy networks of Huntington's disease or Parkinson's disease who tirelessly make efforts to support medical research on these diseases, or women undergoing time and again the infertility treatment procedure (Franklin, 1997: 154-161, 180-183; Novas, 2003: 210-214; Brown, 2003: 7-8) exemplify such a condition of living in hope. In Marxist terms, hope may have the same position in the economy of hightech medicine as labour has in the capitalist production; maybe all value of medical options to make personal existence healthier, better, even 'perfect' is derived from hope. Maybe it is 'hope labour' that the expectations of high-tech medicine require in order to sustain.

\section{Notes}

1 The variation, deriving from differences in national health policies and cultures of health care and medical research and from the range of illnesses and deficiencies involved in this business, is so wide that it would be foolish to present any general pattern of how profit seeking and personal pursuit for health are entangled with each other in life enhancement economy. According to Carl Elliot (2003), the orientation of medicine toward life enhancement and promises of better or 'perfect' life is a particularly American phenomenon, stemming from anxiety-ridden preoccupation with self-presentation and self-fulfilment by which the American culture and morals are impregnated. His claim is intriguing in relation to facts that today the U.S. is the leading country in medical research and forms the major market area for health care products.

\section{References}

Andrews, L. \& Nelkin, D.

2001 Body Bazaar: The Market for Human Tissue in Biotechnology. New York: Crown.

Arendt, $\mathrm{H}$.

1958 The Human Condition. Chicago and London: University of Chicago Press.

Beck-Gernsheim, E.

1996 "Die soziale Konstruktion des Risikos: das Beispiel Pränatal Diagnostik" (The social construction of risks: the example of prenatel diagnostics). Soziale Welt 47, 3: 284-296.

Brown, N.

2003 "Hope Against Hype: Accountability in Biopasts, Presents and Futures." Science Studies 16, 2: 3-21.

Canguilhem, G.

1989 The Normal and the Pathological. New York: Zone.

Chadwick, R.

1999 "Genetics, Choice and Responsibility." Health, Risk \& Society 1, 3: 293-300.

Dean, $\mathrm{M}$.

1996 "Putting the Technological into Government". History of the Human Sciences 9, 3: 47-68.

Elliot, C.

2003 Better Than Well: American Medicine Meets the American Dream. New York \& London: W.W. Norton.

Epstein, S.

1996 Impure Science: AIDS Activism and the Politics of Knowledge. Berkeley: UniFaden, R. versity of California Press.

1991 "Autonomy, Choice, and the New Reproductive Technologies: The Role of Informed Consent in Prenatal Genetic Diagnosis". Pp. 37-48 in Rodin \& Collins (eds.), Women and New Reproductive Technologies: Medical, Psychosocial, Legal and Ethical Dilemmas. Hillsdale, NJ: Lawrence Erlbaum. 
FDA

2003 "FDA Approves Humatrope for Short Stature". FDA Talk Paper, July 25, 2003. http://www.fda.gov/bbs/topics/ANSWERS/2003/ANS01242.html

Foucault, M.

1985 The Use of Pleasure. New York: Pantheon.

1989 The Birth of the Clinic: An Archaeology of Medical Perception. London \& New York: Routledge.

Frank, A.W.

2003 "Connecting Body Parts: Technoluxe, Surgical Shapings and Bioethics". Paper presented at the Vital Politics conference, London School of Economics, September 2003. http://www.lse.ac.uk/ collections/BIOS/vital_politics_ papers.htm

Franklin, S.

1997 Embodied Progress: A Cultural Account of Assisted Conception. London \& New York: Routledge.

2001 "Culturing Biology: Cell Lines for the Second Millenium." Health: 5, 3: 335354.

2003 "Ethical Biocapital: New Strategies of Cell Culture.” Pp. 97-128 in Franklin \& Lock (eds.), Remaking Life and Death: Toward an Anthropology of the Biosciences. Santa Fe: School of American Research Press \& Oxford: James Currey. Franklin, S. \& Lock, M.

2003 "Animation and Cessation: The Remaking of Life and Death." Pp. 3-22 in Franklin \& Lock (eds.), Remaking Life and Death: Toward an Anthropology of the Biosciences. Santa Fe: School of American Research Press \& Oxford: James Currey.

Haraway, D.

1997 Modest_witness@second_millenium. New York: Routledge.

Heidegger, $\mathrm{M}$.

1962 “Die Frage nach der Technik" (Question concerning technology). Pp. 5-36 in Heidegger: Die Technik und die Kehre (Technics and the fold), Tübingen: Neske.

Helén, I.

2002 "Lääketieteen lupaus ja elämän politiikka" (The promise of medicine and politics of life). Sosiologia 39, 2: 104115.

2004 "Technics Over Life: Risk, Ethics and the Existential Condition in High-tech Antenatal Care." Economy and Society 33, 1: 28-51.

Landecker, $\mathrm{H}$.

2003 "On Beginning and Ending with Apoptosis: Cell Death and Biomedicine." Pp. 23-60 in Franklin \& Lock (eds.), Remaking Life and Death: Toward an Anthropology of the Biosciences. Santa Fe: School of American Research Press \& Oxford: James Currey. Lemke, Th.

2000 "Die Regierung der Risiken: Von der Eugenik zur genetischen Gouvernementalität" (Governing the risk: From eugenics to genetic governmentality)'. Pp. 227-264 in Bröckling, Krasmann \& Lemke (eds.), Gouvernementalität der Gegenwart:Studien zurÖ Ökonomisierung des Sozialen (Governmentality of the present: studies on economization of the social). Frankfurt am Main: Suhrkamp.

Löwy, I.

2000 "Trustworthy Knowledge and Desperate Patients: Clinical Tests for New Drugs From Cancer to AIDS”. Pp. 49-81 in Lock, Young \& Cambrosio (eds.), Living and Working with the New Medical Technologies. Cambridge \& New York: Cambridge University Press.

Nelkin, D.

1993 "The Social Power of Genetic Information." Pp. 177-190 in Kevles \& Hood (eds.), The Code of Codes: Scientific and Social Issues in the Human Genome Project. Cambridge, Ma. \& London: Harvard University Press.

Novas, C.

2003 Governing 'Risky' Genes: Predictive Genetics, Counselling Expertise and the Care of the Self. PhD thesis, Department of Sociology, Goldsmiths College, University of London.

Novas, C. \& Rose, N.

2000 "Genetic Risk and the Birth of the Somatic Individual." Economy and Soci- 
ety 29, 4: 485-513.

Pálsson, G.

2002 "Medical Databases. The Icelandic Case”. Pp. 22-41 in Lundin \&_kesson (eds.), Gene Technology and Economy. Lund: Nordic Academic Press.

Pálsson, G. \& Rabinow, P.

1999 "Iceland: The Case of a National Human Genome Project." Anthropology Today 15, 5: 14-18.

Petersen, A.

1998 "The New Genetics and the Politics of Public Health." Critical Public Health 8, 1: 59-71.

1999 “Counselling Genetically 'At-risk': The Poetics and Politics of 'Nondirectiveness.'” Health, risk \& society 1 , 3: 253-266.

Rabeharisoa, V. \& Callon, M.

2002 "The Involvement of Patients' Associations in Research." International Social Science Journal 171:57-65.

Rabinow, P.

1996 "Artificiality and Enlightenment: From Sociobiology to Biosociality." Pp. 91111 in Rabinow: Essays on the Anthropology of Reason. Princeton, NJ.: Princeton University Press.

1998 "Genetic and Molecular Bodies." Pp. 135-186 in Yamamoto (ed.), Philosophical Designs for a Socio-cultural Transformation. Tokyo: E.H.E.S.C.

Rheinberger, $\mathrm{H}-\mathrm{J}$.

1995 "Beyond Nature and Culture: A Note on Medicine in the Age of Molecular Biol-

Rose, $\mathrm{H}$. ogy." Science in Context 8, 1:249-263.

2003 "The Commodification of Virtual Reality: The Icelandic Health Sector Database." Pp. 77-92 in Goodman, Heath \& Lindee (eds.), Genetic Nature/culture: Anthropology and Science Beyond Two-culture Divide. Berkeley et al.: University of California Press.

Rose, N.

1999 Powers of Freedom. Reframing Political Thought. Cambridge \& New York: Cambridge University Press.

2001 “The Politics of Life Itself.” Theory, Culture \& Society 18, 6: 1-30.

Taminiaux, J.

1982 Recoupements (Readjustments). Bruxelles: OUSIA.
Waldby, C.

2000 The Visible Human Project: Informatic Bodies and Posthuman Medicine. London \& New York: Routledge.

Young, A.

1995 The Harmony of Illusions: Inventing Post-traumatic Stress Disorder. Princeton, NJ: Princeton University Press.

Yoxen, E.

1983 The Gene Business: Who Should Control Biotechnology. New York: Harper and Row.

Ilpo Helén

Department of Sociology,

University of Helsinki, Finland

ilpo.helen@helsinki.fi 